\title{
Focusing the uncertainty about nonhuman metacogntion
}

\author{
Robert R. Hampton \\ Emory University
}

Keywords: awareness, cognitive control, confidence, consciousness, declarative,explicit, introspection, memory, memory monitoring, metacognition, metamemory, perception, self-awareness, self-control, self-regulation, uncertainty

It is clear that there is no shortage of uncertainty about metacognition in nonhuman animals. The four papers in this special issue have raised questions about the evidence for metacognition from many perspectives, ranging from concerns about whether existing control procedures unambiguously specify sources of stimulus control, to models that appear to generate metacognitive patterns of performance without explicitly metacognitive components, to critiques of the entire effort on the grounds that there is no mechanism specified for metacognition. The area cannot be criticized for a shortage of critical thinking. Many of the critiques put forward direct attention to aspects of this problem that need more attention, but some of these concerns are more central than others.

The notion that metacognition is "complex" or a form of "higher" cognition is widespread, and concerns about invoking "higher functions" to explain nonhuman behavior were raised directly or indirectly in each paper. But this concern is relevant only if performance in metacognition tasks requires "new" cognitive mechanisms not employed in other behavior. It is not clear that metacognition is more complex than cognition. Metacognition may involve mostly the same mechanisms as other cognition even when it can be shown

Preparation of this manuscript was supported by NIH grant 1RO1MH082819-01A1, by Yerkes Center base grant No. RR00165 awarded by the Animal Resources Program of the National Institutes of Health, and by the Center for Behavioral Neuroscience under the STC Program of the National Science Foundation under Agreement No. IBN-9876754.

Correspondence concerning this article should be addressed to: Robert R. Hampton, Department of Psychology, 532 Kilgo Circle, Emory University, Atlanta, GA, USA. e-mail: robert. hampton@emory.edu that metacognition takes as input private mental states rather than publicly observable stimuli. For an analogy, consider that secondary reinforcement is not necessarily more complex than primary reinforcement, although it cannot occur without primary reinforcement. Both primary and secondary reinforcement are useful constructs in a mechanistic account of behavior. The important question is whether metacognition is similarly useful in describing and explaining behavior, although it is unlikely to have such broad explanatory power as secondary reinforcement. Labeling some mechanisms as "higher" and others as "lower" may interject unhelpful and anthropocentric value judgments into evaluation of our accounts of behavior.

Progress in the study of metacognition in nonhumans may best be advanced through focus on stimulus control. Which stimuli control metacognitive responding (e.g. use of a decline test response, search for more information, accurate confidence judgments) and how is such control established? Are all controlling stimuli public, or can private states such as assessments of memory strength or the vividness of memories also come to control use of a decline test or other metacognitive response? The research reviewed in these papers clearly identifies some interesting behavior not previously documented in nonhumans. This justifies further work on metacognition in nonhumans. In accord with Jozefowiez, Staddon \& Cerutti (2009), I think we should further analyze how these performances come about, without devoting disproportionate effort to developing additional behavioral or theoretical criteria for metacognition. Experiments can proceed and information can accrue without a precise mechanistic definition of metacognition, as in the case of research on "learning" or "perception" which are also difficult to define precisely. In fact, these phenomena are probably 
best defined functionally because a variety of mechanisms underlie them. Maintaining a broad functional definition can be a strength that brings related findings together rather than a weakness reflecting insufficient theoretical groundwork. However, part of the process will be making distinctions between performances that do capture theoretically interesting differences. One example might be the distinction between metacognition based on publicly observable stimuli and that based on private mental events. By controlling for and manipulating particular sources of stimulus control, such as stimulus identity, response latency, generalization, and memory we will be able to determine experimentally which stimuli enter into metacognition under which conditions.

It seems unlikely that substantial progress will be made in elucidating the processes underlying metacognition by trying to eliminate the influence of reinforcement (Smith, Beran, Couchman, Coutinho \& Boomer, 2009). Reinforcement, in one form or another, is the only way in which instructions can be given to nonverbal species. Unless it is useful in maximizing reinforcement in one form or another (increasing quality or quantity of food, decreasing delays or effort) there is simply no reason for an animal to use a metacognitive response. Indeed, as indicated by Smith et. al., our job is to "come to understand the cognitive representations and processes that allow this maximization to occur."

Three of the four papers on this issue make extensive use of modeling in an attempt to understand the performances observed. The Behavioral Economic Model (BEM; Jozefowiez, et al., 2009) formalizes competition between responses and therefore shares some core explanatory features with the much less formal account of the performance of monkeys searching for food in the "tubes task" offered by Hampton, Zivin \& Murray (2004). At least two relevant questions arise from these analyses that emphasize competition. First, if these analyses are correct, do they invalidate the conclusion that the subjects' performances demonstrate metacognition? Or do they rather provide a possible explanation of some human and nonhuman metacognitive performances? Second, can competition models work when the opportunity to decline tests is offered before presentation of tests and the two types of response are not in direct competition (as in Hampton, 2001)? If not, what does this tell us about the decision process underlying such prospective metacognition?

Finally, it will be interesting to see more explicitly comparative work on metacognition, particularly experiments that use identical procedures with different species. It might be expected that associative and competitive process like those formalized in the BEM model would be shared by many distantly related species. It is early to tell but it appears that some species (humans and old world monkeys) may more readily show a metacognitive pattern of perfor- mance than do other species (pigeons and new world monkeys) that would be expected to share the mechanisms articulated in BEM (Beran, Smith, Coutinho, Couchman \& Boomer, in press; Basile, Hampton, et al., 2009; Sutton and Shettleworth 2008). There are, of course, many reasons that any given test of metacognition would be negative. However, if a pattern of species differences is established that appears to have some cognitive (rather than motivational or perceptual) basis, other comparisons between those species will help identify the necessary conditions for metacognition and the selective pressures responsible for its evolution.

\section{References}

Basile, B. M., Hampton, R. R., Suomi, S., \& Murray, E. A. (2009). An assessment of memory awareness in tufted capuchin monkeys (Cebus apella). Animal Cognition, 12, 169-180. doi:10.1007/s10071-008-0180-1

Beran, M. J., Smith, J. D., Coutinho, M. V. C., Couchman, J. J., Boomer, J. (in press). The psychological organization of "uncertainty" responses and "middle" responses: A dissociation in capuchin monkeys (Cebus apella). Journal of Experimental Psychology: Animal Behavior Processes.

Hampton, R. R. (2001). "Rhesus monkeys know when they remember." Proceedings of the National Academy of Sciences of the United States of America, 98, 5359-5362. doi:10.1073/pnas.071600998

Hampton, R. R., Zivin, A., \& Murray, E. A. (2004). "Rhesus monkeys (Macaca mulatta) discriminate between knowing and not knowing and collect information as needed before acting." Animal Cognition, 7, 239-254. doi:10.1007/s10071-004-0215-1

Jozefowiez, J., Staddon, J.E.R. \& Cerutti, C.T. (2009). Metacognition in animals: how do we know that they know? Comparative Cognition and Behavior Reviews, 4, 29-39. Smith, J.D., Beran, M.J., Couchman, J.J., Coutinho, M.V.C. \& Boomer, J.B. (2009). Animal metacognition: Problems and prospects. Comparative Cognition and Behavior Reviews, 4, 40-53.

Sutton, J. E. and S. J. Shettleworth (2008). "Memory without awareness: Pigeons do not show metamemory in delayed matching to sample." Journal of Experimental Psychology-Animal Behavior Processes, 34, 266-282.

doi:10.1037/0097-7403.34.2.266 